\title{
The effect of iron deficiency on the stomach of the rat
}

\author{
By L. S. VALBERG, K. B. TAYLOR AND L. J. WITTS \\ Nuffield Department of Clinical Medicine, University of Oxford \\ AND W. C. D. RICHARDS \\ Department of Pathology, The Radcliffe Infirmary, Oxford \\ (Received 19 October 1960-Revised I7 March 1961)
}

Iron deficiency in man has long been known to produce changes in certain epithelial structures such as the nails, tongue, mouth and oesophagus. The association of hypochromic anaemia with achlorhydria was first described in the early part of this century (Faber, 1913), and since then the results of many studies have indicated that achlorhydria and chronic gastritis are unduly frequent in patients with irondeficiency anaemia (Witts, 1959). Although all writers acknowledge the association of gastric abnormalities with iron deficiency there is much controversy as to whether the gastric disorder is the result or the cause of the iron deficiency, and many hypotheses have been put forward in an attempt to explain their association.

In these circumstances it would seem natural to study the problem by experiments on animals. Surprisingly enough, there have been no previous reports of functional or structural studies on the stomach of iron-deficient animals apart from a preliminary communication by Taylor \& Witts (1958). The present paper deals with the secretion of $\mathrm{HCl}$ and pepsin in experimental iron deficiency in the rat and with histological studies of its gastro-intestinal tract. Observations on the secretion of intrinsic factor in experimental iron deficiency will be reported in a subsequent paper.

\section{EXPERIMENTAL}

\section{Animals and their diets}

Iron deficiency was induced in rats by means of a semi-synthetic diet and a scrupulous elimination of all iron-containing materials from the immediate environment of the animals. It was not found necessary to use rats reared from iron-deficient mothers or to restrict the iron intake of the offspring before weaning. The irondeficient diet was composed of $65 \%$ spray-dried skim-milk powder, $20 \%$ sucrose, $8 \%$ lard, $2 \%$ arachis oil, and supplements of vitamins and minerals (Tables $I$ and 2 ). It contained per $\mathrm{kg}: \mathrm{I}_{4} \cdot \mathrm{mg}$ iron, $0.04 \mathrm{mg}$ cobalt and $30 \mu \mathrm{g}$ vitamin $\mathrm{B}_{12}$. The control diet differed only in its iron supplement; it contained $250 \mathrm{mg}$ iron $/ \mathrm{kg}$ and the cobalt content, measured by neutron-activation analysis, was $0.18 \mathrm{mg} / \mathrm{kg}$. This supplemented diet was found to be adequate for growth and reproduction through at least two generations.

The rats were housed in specially designed Perspex cages with wide-mesh aluminium 
floors. They were fed once each day and glass-distilled water was offered in excess of demand. Since it was essential to have animals of a size sufficient to permit gastric intubation, the iron-deficient animals were transferred to a diet containing $2.5 \mathrm{mg}$ iron $/ \mathrm{kg}$ when the level of haemoglobin fell to $6.0 \mathrm{~g} / 100 \mathrm{ml}$ or less. Whenever the haemoglobin rose to $9.0 \mathrm{~g} / 100 \mathrm{ml}$ the rats were returned to the iron-deficient diet. In this way a sustained anaemia was induced, mortality was avoided and growth was satisfactory.

Table I. General composition of the diet

$\begin{array}{lr}\text { Spray-dried skim milk (g) } & 650 \\ \text { Sucrose (g) } & 205 \\ \text { Fat mixture (I part arachis oil, 3 parts lard) (g) } & 99 \\ \text { Water-soluble vitamins mixture (g) } & \text { I0 } \\ \text { Fat-soluble vitamins mixture (ml) } & \text { I } \\ \text { Choline dihydrogen citrate (g) } & 5 \\ \text { Salt mixture* (g) } & 30\end{array}$

* I $\mathrm{kg}$ contained sodium chloride $200 \mathrm{~g}$, sodium iodate $\left(\mathrm{NaIO}_{3} \cdot \mathrm{H}_{2} \mathrm{O}\right) 22 \mathrm{mg}$, manganese sulphate $\left(\mathrm{MnSO}_{4} .4 \mathrm{H}_{2} \mathrm{O}\right)$ 10.8I g, copper sulphate $\left(\mathrm{CuSO}_{4} \cdot \mathrm{H}_{2} \mathrm{O}\right) 2.72 \mathrm{~g}$ and dextrose $786.45 \mathrm{~g}$. The ironsupplemented salt mixture contained $58.08 \mathrm{~g}$ of ferrous ammonium sulphate in place of an equivalent amount of dextrose.

\section{Table 2. Vitamin mixtures}

\begin{tabular}{|c|c|}
\hline \multicolumn{2}{|l|}{ Water-soluble } \\
\hline Calcium pantothenate $(\mathrm{g})$ & $1 \cdot 200$ \\
\hline Pyridoxine (g) & 0.500 \\
\hline Riboflavin (g) & 0.500 \\
\hline Thiamine hydrochloride $(\mathrm{g})$ & $1 \cdot 000$ \\
\hline Nicotinic acid (g) & $1 \cdot 000$ \\
\hline Vitamin $\mathrm{K}(\mathrm{g})$ & 0.100 \\
\hline Folic acid (g) & 0.100 \\
\hline$p$-Aminobenzoic acid (g) & I.000 \\
\hline Biotin (g) & 0.020 \\
\hline Inositol (g) & $20 \cdot 000$ \\
\hline Vitamin $\mathbf{B}_{12}(\mathrm{~g})$ & 0.0015 \\
\hline Dextrose $(g)$ & $974 \cdot 5785$ \\
\hline \multicolumn{2}{|l|}{ Fat-soluble } \\
\hline palmitate (g) & $0^{\circ} 40$ \\
\hline Calciferol (g) & 0.05 \\
\hline$\alpha$-Tocopherol $(35 \%)$ & $50 \cdot 00$ \\
\hline
\end{tabular}

Twelve litters of weanling female albino rats of the Wistar strain were divided into two groups of thirty-six and twenty-four animals in such a way that each litter was proportionally represented; the larger group was given the iron-deficient and the smaller group the iron-supplemented diet. The animals in the iron-deficient group were divided at intervals of 2 weeks according to their haemoglobin levels; those with levels below $6.0 \mathrm{~g} / 100 \mathrm{ml}$ were housed together and given a diet containing $2.5 \mathrm{mg}$ iron $/ \mathrm{kg}$ until their haemoglobin levels rose to $9.0 \mathrm{~g} / 100 \mathrm{ml}$; animals with haemoglobin levels of $6.0 \mathrm{~g} / 100 \mathrm{ml}$ or higher were maintained on the diet with $1.4 \mathrm{mg}$ iron $/ \mathrm{kg}$. No more than ten animals were housed in each cage. 


\section{Sampling and analysis}

Haemoglobin. The tail of the rat was warmed in water, wiped dry with cotton-wool and the dorsal vein was cut with a scalpel. A total of $0.025 \mathrm{ml}$ of blood, obtained with a calibrated pipette, was diluted in $6.0 \mathrm{ml}$ of $0.048 \%(\mathrm{w} / \mathrm{v})$ ammonia and the optical density of the solution was measured at $55^{\circ} \mathrm{m} \mu$. Evaluation of the method showed a coefficient of variation of $5 \%$.

Haematocrit. Venous blood from the tail was drawn into a heparinized capillary tube of uniform bore. The tube was sealed and spun at $12000 \mathrm{~g}$ for $5 \mathrm{~min}$ in a microhaematocrit centrifuge. The coefficient of variation of this method was $4 \%$.

Plasma iron. This was measured by a modification of the standard thiocyanate method in the Department of Biochemistry at the Radcliffe Infirmary.

Gastric contents. Measurements of the volume and acid and pepsin contents of gastric secretion were made in seventeen animals from the deficient group and a similar number of controls when the animals were 120 days old, and in fourteen of each when 220 days old. Specimens of gastric juice were obtained by a technique that did not involve anaesthetizing the animal (Valberg \& Witts, I96I). Histamine in a dose of $50 \mathrm{mg} / \mathrm{kg}$ was used as a gastric stimulant.

The acid concentration of the gastric contents was measured by electrometric titration with $0.0 \mathrm{I} \mathrm{N}$ sodium hydroxide. Proteolytic activity was measured by incubating the gastric juice with bovine albumin under standard conditions. The undigested protein was precipitated with trichloroacetic acid and the extinction coefficient of the supernatant liquid was measured at $276 \mathrm{~m} \mu$ (Valberg \& Witts, I96r).

\section{Histological studies}

The rats were killed by the removal of blood from the descending aorta, under ether anaesthesia. The stomachs were quickly removed and opened along the greater curvature. They were pinned out on cork boards and then fixed in formol-saline. Three transverse sections were taken from the proximal, central and distal parts of the glandular portion of the stomach and a map was made showing the specific sites from which specimens had been taken. The sections were stained with haematoxylin and eosin, mucicarmine, and Periodic Acid Schiff stain.

\section{RESULTS}

The iron-deficient animals were easily distinguished from their controls given supplements of iron. They tended to be lethargic and to fall asleep easily if undisturbed, though they were active and playful when handled. Their coats, particularly during the period of rapid growth, were shabbier and their hair appeared to grow unevenly. Their eyes showed a transparent pallor and their incisor teeth were pearly-white in colour in comparison with the golden-yellow teeth of the animals given the iron supplement. Loose stools were observed in both groups of rats for 4 or 5 days after they had first received the diet; diarrhoea completely subsided in the group given the 
supplement but a few of the iron-deficient animals continued to have poorly formed stools.

The mean weight gains of the deficient and control rats are shown in Fig. $I$ and the mean haemoglobin concentrations of the two groups are given in Fig. 2. The deficient animals grew nearly as well as the animals given the iron supplement. The haemoglobin levels of the controls, in contrast to the iron-deficient group, rose progressively to a peak about the 7oth day and thereafter declined slightly. The levels of haemoglobin of our adult rats were higher than the values reported in the literature (Williamson \& Ets, 1926; Cameron \& Watson, 1949; Beutler, 1957). The disparity is possibly due to

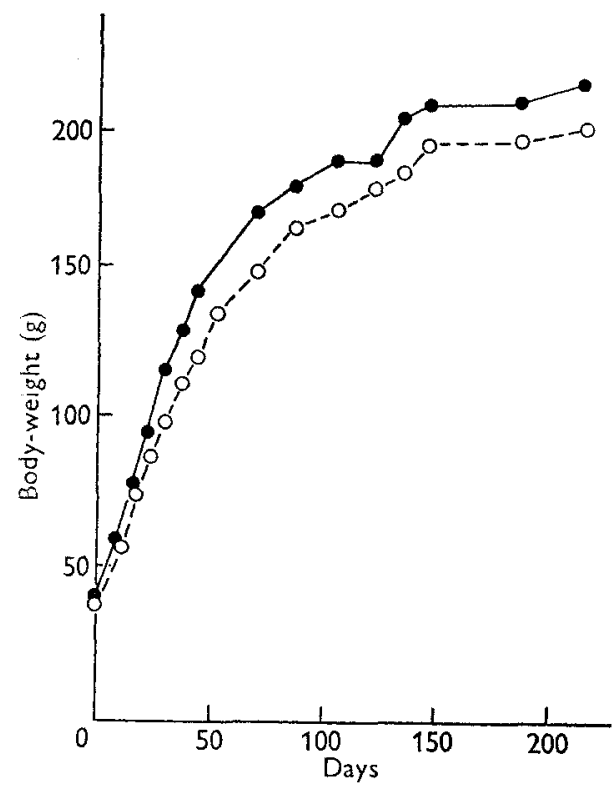

Fig. I

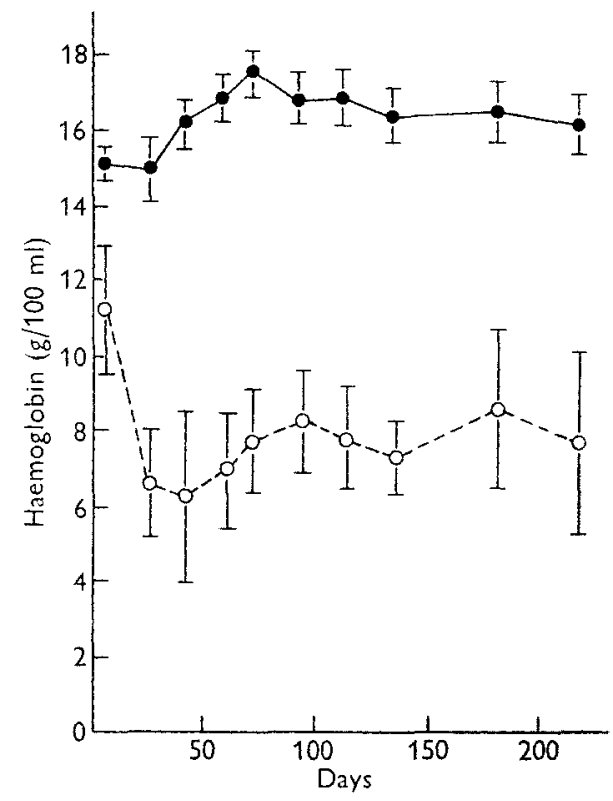

Fig 2

Fig. I. Weight gain of control and iron-deficient rats. - - control; $0 \cdots 0$, deficient.

Fig. 2. Haemoglobin concentration of control and iron-deficient rats, with standard errors of means. -O, control; $0 \cdots-. .0$, deficient.

differences in the strain of animal and the composition of the diets, and to the absence of endemic infection in our animals. The mean haemoglobin concentration of the iron-deficient group remained between 6 and $9 \mathrm{~g} / 100 \mathrm{ml}$ throughout the experiment. Other evidence of iron deficiency in our rats was provided by the low mean corpuscular haemoglobin concentrations, the low levels of plasma iron and the absence of pigment from their incisor teeth (Table 3).

\section{Gastric secretion}

The results of analysis of gastric secretion, performed when the animals were 120 and 220 days of age, are given in Table 3 . The volume of gastric secretion and the rate of gastric emptying were similar in the iron-deficient and control groups. 
The iron-deficient animals appeared to secrete more pepsin than the control animals when tested at 120 and 220 days, but the differences between the means of the two groups did not achieve statistical significance.

The results of tests of acid secretion made when the animals were 120 days old showed a difference between the two groups, the production of acid being reduced in the iron-deficient animals. The difference was significant within the $5 \%$ level on the basis of the two-tail test. The same trend was observed when the animals were 220 days old, but the difference between the means was less marked.

Table 3. Mean values, with their standard errors where applicable, for results of analysis of gastric secretion of rats on a diet adequate or deficient in iron

Age of rats (days)

Diet

No. of rats

Weight (g)

Haemoglobin (g/100 ml)

Mean corpuscular haemoglobin concentration (\%)

Plasma iron $(\mu \mathrm{g} / 100 \mathrm{ml})$

Gastric emptying (\%)*

Gastric secretion (ml/rat)

$\mathrm{pH}$ of gastric contents (units)

Acid secreted ( $\mu$-equiv./rat)

Pepsin secreted (units/rat) $†$

$\begin{array}{cc}\overbrace{\text { Fe }(+)} & \text { Fe (-) } \\ 17 & 17 \\ 180 & 160 \\ 16.7 & 8.2 \\ 35 & 27 \\ - & - \\ 46 \pm 4.5 & 42 \pm 3.3 \\ 1.5 \pm 0.26 & 1.8 \pm 0.21 \\ 1.69 \pm 0.062 & 1.85 \pm 0.085 \\ 189 \pm 20 & 139 \pm 14 \\ 66 \pm 9 & 85 \pm 11\end{array}$

$\begin{array}{cc}\text { Fe }(+) & \text { Fe }(-) \\ 14 & 14 \\ 219 & 202 \\ 16 \cdot 5 & 8 \cdot 7 \\ 36 & 29 \\ 246 & 23 \\ 53 \pm 4.3 & 41 \pm 4.5 \\ 1 \cdot 9 \pm 0 \cdot 19 & 2 \cdot 1 \pm 0 \cdot 20 \\ 1 \cdot 72 \pm 0.092 & 1 \cdot 85 \pm 0.133 \\ 190 \pm 20 & 169 \pm 19 \\ 82 \pm 3 & 94 \pm 6\end{array}$

* Percentage of gastric contents passing into the intestine in $45 \mathrm{~min}$.

$\uparrow$ A unit of pepsin is defined as that amount which, when incubated with albumin substrate, liberates $6.0 \times 10^{-4}$ m-equiv, of tyrosine-like substance in $1 \mathrm{ml}$ of supernatant liquid.

Because of the way in which the animals were re-allocated to different groups at bimonthly intervals, depending on their haemoglobin concentration, and because animals were placed in individual cages from time to time, it has not been possible to consider either group differences or litter differences in the statistical analysis of these results, and it was therefore thought more appropriate to present them as they stand.

No correlation was observed between body-weight and the volume of gastric secretion, total acid secretion or pepsin production.

\section{Morbid anatomy}

No change was noted in the appearance of the nails, mouth, tongue, oesophagus or small intestine of the iron-deficient animals. The caecums of the rats fed on the irondeficient diet were two to three times larger than those of animals reared on the iron supplemented ration. In one instance an enlarged caecum produced volvulus. The spleen and heart were larger in the iron-deficient animals but no abnormality was noted in the other organs on macroscopic examination.

The gastric mucosa of the iron-deficient animals was very pale but otherwise the gross appearance of the stomach was similar to that of the controls. The stomach of the rat differs from that of man in that the proximal half, or rumen, is lined by stratified squamous epithelium. The glandular portion comprises the distal part and it is 
divided into an upper portion that contains the parietal and chief cells and a lower portion that forms the antrum. The antrum contains no parietal cells and it extends upward along the lesser curvature where it meets the stratified squamous epithelium of the rumen in the vicinity of the oesophageal opening.

Microscopic examination of the gastric mucosa of the group given the iron supplement showed no abnormality and there were no gastric erosions. The gastric mucosa of the iron-deficient rats also appeared to be intact. There was no evidence of gastritis or of gastric atrophy, and no change was found in the appearance of the parietal or chief cells. Histological sections taken from the tongue, upper oesophagus, duodenum, jejunum and ileum of the rats on the iron-deficient diet showed no abnormality.

Sections of the caecums of the iron-deficient rats showed no evidence of ulceration, inflammation or neoplasm; ganglion cells were present in the muscularis. The appearances suggested simple distension, for which no obvious cause was found.

\section{DISCUSSION}

There has been curiously little experimental work on the effects of iron deficiency on animals except in relation to erythropoiesis. Schmidt (1928) noted cardiac hypertrophy and changes in the coat and whiskers of iron-deficient mice but made no mention of changes in the gastro-intestinal tract. Hahn \& Whipple (1936), in their studies of experimental anaemia, found no changes in the nails, tongue, mouth or oesophagus of iron-deficient dogs. Mice reared on a diet of whole cow's milk have been reported to develop histological changes in the oesophagus in the form of marked hyperkeratinization with proliferation of epithelial cells and an increase in the number of mitotic figures (Cordray, 1940). To interpret these results as being solely due to iron deficiency is rather hazardous since cow's milk has a low content of copper, manganese and vitamin $\mathrm{E}$, all of which are required by the mouse.

There have been few studies of the relation of nutrition to gastric function in the rat. Dyer \& Roe (194 $a, b)$ reported that neither acute nor chronic deprivation of either vitamin A or thiamine had any effect on gastric secretion. Shay, Komarov, Gruenstein \& Fels (1946) were unable to detect any changes in the gastric secretion of rats severely depleted of thiamine. They did note, however, that gastric ulceration after the test-meal procedures was more common in the depleted animals than in the controls. In our rats there were not only no gross changes in the stomach but none in the mouth, tongue or nails. The only gross change observed was in the size of the caecum, the colour of the teeth and the character of the coat.

At 120 days from birth the mean acid secretion expressed in $\mu$-equiv. per rat was reduced in the iron-deficient animals in comparison with the control group. Since the control animals were $9 \%$ larger than the deficient animals, the relationship of body size to acid secretion was evaluated. No correlation was observed between bodyweight and total acid secretion, with the exception that the three smallest animals in the iron-deficient group secreted 96,89 and $55 \mu$-equiv. of acid respectively.

The failure of iron deficiency to produce abnormalities in gastric structure in the 
rat is in contrast to the findings in man, in whom achlorhydria and gastritis are frequent in iron deficiency. As far as they go the experiments do not support the hypothesis that gastritis is the result rather than one of the causes of iron deficiency in man. However, the duration of iron deficiency differed greatly in the animal experiments and in the disease in man. It is probable that the duration of iron deficiency is crucial in determining whether abnormalities occur in epithelial structures. The rate of turnover of cells is probably similar in the alimentary tract in rat and man (Bertalanffy \& Nagy, I958). In human beings epithelial changes are found usually only after a number of years. In women, glossitis, dysphagia and achlorhydria are all more common over the age of 30 . In young men with iron deficiency, achlorhydria is unduly common and improves after treatment (Leonard, 1954; Brumfitt, I960) but in them, too, iron deficiency has probably been present for a number of years and has become manifest as the result of the spurt of growth in adolescence. In our study in the rat there were no changes in the nails and the epithelium of the tongue, where it is generally agreed that lesions are produced by iron deficiency in man, and therefore the absence of gross changes in the stomach cannot be regarded as conclusive evidence that the lesions in the human stomach are not due to iron deficiency.

There are, of course, other differences between these rats and human beings with iron deficiency. All other nutritional principles were supplied in amounts believed to be optimal and the diet was bland and non-irritating. There may also be a species difference in the response to iron deficiency; a number of facts suggest that in man genetic factors may be important (Witts, 1959).

\section{SUMMARY}

I. Iron deficiency was produced in thirty-six rats by placing them after weaning on a diet containing only $\mathrm{I} \cdot 4 \mathrm{mg}$ of iron/ $\mathrm{kg}$ but adequate in all other respects. Twentyfour control animals were given the same diet supplemented with iron.

2. The iron-deficient animals developed a hypochromic, microcytic anaemia.

3. Studies were made of gastric function. The volume of gastric secretion was unaffected by iron deficiency. The secretion of pepsin appeared to be raised in the iron-deficient animals, but differences between the two groups were not statistically significant. The secretion of acid was reduced in the iron-deficient animals at 120 and at 220 days, the difference from normal being more marked at 120 days.

4. No macroscopic or microscopic changes were found in the nails, mouth or tongue, oesophagus, stomach or small intestine. The caecums of the iron-deficient animals were grossly enlarged.

5. Changes in epithelial structures and in the gastric mucosa attributable to iron deficiency in man probably require a much longer duration of iron deficiency than is possible in the rat.

We are indebted to Dr G. H. Spray for the estimation of vitamin $B_{12}$ in the diet, Miss B. M. Mallett for haematological tests, Mr G. E. Newman for the estimations of plasma iron, Mr B. O. Bartlett for statistical advice, Mr J. R. P. O'Brien for biochemical 
advice, and $\mathrm{Mr} \mathrm{J}$. Halfacree and the technical staff of the Department for a great deal of assistance.

The work was supported by a grant to L. J.W. from the Medical Research Council, and L. S. V. held a Medical Research Fellowship of the National Research Council of Canada.

\section{REFERENCES}

Bertalanffy, F. D. \& Nagy, K. (1958). Anat. Rec. 130, 27 r.

Beutler, E. (1957). Amer. F. med. Sci. 234, 517.

Brumfitt, W. (1960). Quart. F. Med. 29, I.

Cameron, D. G. \& Watson, G. M. (1949). Blood, 4, 816.

Cordray, D. P. (1940). Ann. Otol., etc., St Louis, 49, 160.

Dyer, H. M. \& Roe, J. H. (1941 a). Amer. F. dig. Dis. 8, 329.

Dyer, H. M. \& Roe, J. H. (1941 b). Amer. F. dig. Dis. 8, 333.

Faber, K. (1913). Berl. klin. Wschr. 50, 958.

Hahn, P. F. \& Whipple, G. H. (1936). Amer. F. med. Sci. 191, 24.

Leonard, B. J. (1954). Lancet, 266, 899.

Shay, H., Komarov, S. A., Gruenstein, M. \& Fels, S. S. (1946). Gastroenterology, 6, 199.

Schmidt, M. B. (1928). Der Einfluss eisenarmer und eisenreicher Nährung auf Blut und Körper. Jena: Gustav Fischer.

Taylor, K. B. \& Witts, L. J. (1958). Quart. F. Med. 27, 565.

Valberg, L. S. \& Witts, L. J. (196r). Gut, 2, 32.

Williamson, C. S. \& Ets, H. N. (1926). Amer. F. Physiol. 77, 480.

Witts, L. J. (1959). Canad. med. Serv. F. 15, 645. 